\title{
Semi-Quantification of Lectins in Rice (Oryza sativa L.) Genotypes via Hemagglutination
}

\author{
Haseena Gulzar ${ }^{1}$, Muhammad Asif Nawaz ${ }^{1}\left(\mathbb{D}\right.$, Asad Jan ${ }^{2}{ }^{(0)}$, Farhat Ali Khan ${ }^{3}$, Sumaira Naz ${ }^{4}$, \\ Muhammad Zahoor ${ }^{4, *(1)}$, Dil Naz ${ }^{5}$, Riaz Ullah ${ }^{6}\left(\mathbb{D}\right.$, , Essam A. Ali ${ }^{7}$ and Hidayat Hussain ${ }^{8}(1)$ \\ 1 Department of Biotechnology, Shaheed Benazir Bhutto University, Sheringal Dir Upper, \\ Peshawar 18000, Khyber Pakhtunkhwa, Pakistan; haseenagulzar@sbbu.edu.pk (H.G.); \\ asif_biotech33@sbbu.edu.pk (M.A.N.) \\ 2 Institute of Biotechnology and Genetic Engineering, Agriculture University Peshawar, \\ Peshawar 18000, Khyber Pakhtunkhwa, Pakistan; janasad@aup.edu.pk \\ 3 Department of Pharmacy, Shaheed Benazir Bhutto University, Sheringal Dir Upper, \\ Peshawar 18000, Khyber Pakhtunkhwa, Pakistan; Farhatkhan2k9@yahoo.com \\ 4 Department of Biochemistry, University of Malakand, Chakdara Dir Lower, \\ Malakand 18800, Khyber Pakhtunkhwa, Pakistan; sumaira.biochem@gmail.com \\ 5 Department of Zoology, University of Malakand, Chakdara Dir Lower, \\ Malakand 18800, Khyber Pakhtunkhwa, Pakistan; dilnaz.uom@gmail.com \\ 6 Department of Pharmacognosy, College of Pharmacy, King Saud University, Riyadh 11451, Saudi Arabia; \\ rullah@ksu.edu.sa \\ 7 Department of Pharmaceutical Chemistry, College of Pharmacy, King Saud University, \\ Riyadh 11451, Saudi Arabia; esali@ksu.edu.sa \\ 8 Department of Bioorganic Chemistry, Leibniz Institute of Plant Biochemistry, Weinberg 3, \\ D-06120 Halle (Salle), Germany; Hidayat.Hussain@ipb-halle.de \\ check for \\ updates \\ * Correspondence: mohammadzahoorus@yahoo.com or zahoor@uom.edu.pk
}

Citation: Gulzar, H.; Nawaz, M.A.; Jan, A.; Khan, F.A.; Naz, S.; Zahoor, M.; Naz, D.; Ullah, R.; Ali, E.A.; Hussain, H. Semi-Quantification of Lectins in Rice (Oryza sativa L.) Genotypes via Hemagglutination. Agronomy 2021, 11, 1899. https:// doi.org/10.3390/agronomy11101899

Academic Editor: Richard G. F. Visser

Received: 20 August 2021

Accepted: 17 September 2021

Published: 22 September 2021

Publisher's Note: MDPI stays neutral with regard to jurisdictional claims in published maps and institutional affiliations.

Copyright: (c) 2021 by the authors. Licensee MDPI, Basel, Switzerland. This article is an open access article distributed under the terms and conditions of the Creative Commons Attribution (CC BY) license (https:// creativecommons.org/licenses/by/ $4.0 /)$.

\begin{abstract}
Lectins are unique glycoproteins that react with specific sugar residues on cell surfaces resulting in agglutination. They offer enormous applications in therapeutics, diagnostics, medicine, and agriculture. Rice lectins are naturally expressed during biotic and abiotic stresses suggesting their importance in stress resistance physiology. The objective of this study was to determine the presence and relative concentration of lectins in different accessions of rice obtained from IABGR/NARC Islamabad mainly originated from Pakistan. About 210 rice accessions including 02 local varieties and 05 transgenic seeds were screened for seed lectins using a hemagglutination (HA) assay with $5 \%$ Californian bred rabbits' erythrocytes. A protein concentration of 3-8 mg/100 $\mathrm{mg}$ of seed flour was measured for all the rice accessions; the highest was $8.03 \mathrm{mg}$ for accession 7600 , while the lowest noted was $3.05 \mathrm{mg}$ for accession 7753. Out of 210 accessions, 106 showed the highest HA activity. These 106 genotypes were further screened for titer analysis and specific activity. The highest titer and specific activity were observed for accession 7271 as 1024 and 236 hemagglutination unit (HAU), respectively. The selected accessions' relative affinity and HA capability were evaluated using blood from four different sources: human, broiler chicken, local rabbit, and Californian-breed rabbit. The highest HA activity was observed with Californian-breed rabbit RBCs. The lectin assay was stable for about $1-2 \mathrm{~h}$. After the required investigations, the accessions with higher lectin concentration and HA capability could be used as a readily available source of lectins for further characterization and utilization in crop improvement programs.
\end{abstract}

Keywords: rice; Oryza sativa L.; lectins; hemagglutination assay; rabbit RBCs; titer values; specific activity

\section{Introduction}

Lectins are carbohydrate-binding proteins present in every form of life. These are non-immune in origin and can recognize and bind unique sugars present on cell surfaces, resulting in cell agglutination. These are major glycoproteins that react with specific 
saccharide residues in the cell membranes offering various applications in therapeutics, diagnostics, the food industry, plant breeding, agriculture, and biotechnology. The potential applications of plant lectins in glycobiology, medicines, and agriculture have been studied and reported. Plant lectins are produced commercially for their use in histochemistry, cytochemistry, blotting, affinity chromatography, biosensors, and microarray technologies [1-7].

Oryza sativa L. is a salt-sensitive plant species with significant genetic variability within the cultivated gene pool that can be exploited to develop salt-resistant varieties. The effectiveness of plant lectins on pathogenic fungi, insects, HIV, and cancer, as observed for numerous legume lectins, also needs to be explored for other plant species [8-11]. More than a hundred lectin molecules have been isolated from plants, viruses, bacteria, invertebrates, and vertebrates, including mammals. About 18 different types of lectins of plants are reported to have immunomodulatory effect in case of infection or disease such as cancer [12]. The role of lectins in abiotic and biotic stress resistance in rice has been highlighted by many researchers [13-21]. Knowing about the genes encoding these lectins and their role in plant defense offers many applications in plant breeding and genetic engineering to improve cultivars. Differences in lectin structure and carbohydrate specificity are related to their different functions. Depending on carbohydrate specificity, major lectins are divided into mannose-binding lectins, galactose, $\mathrm{N}$-acetyl galactosamine binding lectins, $\mathrm{N}$-acetylglucosamine binding lectins, $\mathrm{N}$-acetyl neuraminic acid-binding lectins, and fucose binding lectins. Plant defense is the primary application of plant lectins in response to biotic and abiotic stresses [22-24]. The product of a novel rice gene 'RAB21', induced by abscisic acid and water stress, express a protein 'Rab $21^{\prime}[25,26]$ and organspecific expression of another rice gene 'SALT' in response to salt stress and drought clarifies the activation of specific genes during stress conditions [15-20].

Moreover, the regulation of the salt-responsive gene SALT from rice by hormonal and developmental signals showed the differential expression of these genes. The amino acid sequence of rice protein encoded by three genes (a gene SALT (length 145), SALT, and OsJ_01682) showed 100\% similarity [16-19]. Jiang et al. examined the evolutionary history of lectins in rice, Arabidopsis, and soybean and their expression analysis from fulllength cDNA, expression sequence tag (EST), microarray, and massively parallel signature sequencing (MPSS) datasets. There are 267 lectin coding genes in rice, of which 254 have been confirmed by expression profiles, which belong to two families, i.e., B- lectin (mannosebinding lectins) and leg-B (legume lectins). Of 267 genes, 91 are related to biotic stresses, 68 to abiotic stresses such as cold, drought, salinity, and 109 genes to biotic and / abiotic stresses. Lectin expression has also been found to be tissue-specific. Data analyses (MPSS database methods) have shown that after infection by the fungus (Megnaporthe grisea) and bacterium (Xanthomonas oryzae), a total of 58 and 62 lectin genes were differentially expressed, respectively, among which both of the pathogens induced regulation of 29 genes [23]. Various lectin engineering methods are available, by which specificity and stability of a known lectin scaffold could be improved, and non-lectin proteins maybe modified to acquire a sugar-binding function [27]. Hemagglutination (HA) assays are a convenient and quick way of measuring the presence and amount of lectin molecules in a given sample. Lectins of any origin, including multivalent plant lectins, can bind the sialic acid on RBC surfaces and cause blood agglutination. HA is a very convenient method to detect these entities in laboratory settings. Classically, a visual observation method is widely employed in laboratories for routine coagulation assays due to their simplicity. Visual observations in microplates can readily determine hemagglutination titer [28-37]. This study aimed to assess the presence of seed storage lectins in various rice accessions mainly originated from Pakistan without stress to know the inherent capability of rice genotypes expressing phyto-agglutinin. 


\section{Materials and Methods}

The study was carried out in the Institute of Biotechnology and Genetic Engineering (IBGE), Agricultural University Peshawar (AUP), Khyber Pakhtunkhwa, Pakistan.

\subsection{Collection of Plant Material}

A total of 210 rice accessions (Table 1) were obtained from IABGR/NARC Islamabad and tested for lectins' presence using HA. Two local varieties, viz., Fakhre Malakand and Boti, and five transgenic rice seeds, making a total of 217 genotypes, were also screened for the existence of lectins for the purpose of comparison with the wild. Gum Arabic (Sigma Aldrich, St. Louis, MO, USA) was used as positive control and simple PBS as a blank. Out of 210 accessions of rice seeds provided by IABGR/NARC Islamabad, only four originated from China, 186 from Pakistan, 12 from IRRI, and the source of 8 accessions was not mentioned in the catalog. Out of 186 accessions originating in Pakistan, 172 belong to Khyber Pakhtunkhwa province, 04 from Punjab, 02 from AJK, 01 from Gilgit Baltistan, and the source provinces of 07 were unknown (Table 1).

Table 1. Rice (Oryza sativa L.) genotypes used, provided by IABGR/NARC Islamabad.

\begin{tabular}{|c|c|c|c|c|}
\hline S. No & Accession No. & Country, Year of Release & $\begin{array}{c}\text { Province/ } \\
\text { Donor No/Area }\end{array}$ & District \\
\hline $1-4$ & $7216-7219$ & China, 1983 & $\begin{array}{c}\text { C-12, C-13, C-14, C-15 } \\
\text { respectively }\end{array}$ & NA \\
\hline 5 & 7225 & Pakistan, 1983 & Punjab & Sheikhupura \\
\hline 6 & 7234 & // & Khyber Pakhtunkhwa & Unknown \\
\hline 7 & 7235 & // & // & Malakand \\
\hline $8-11$ & $7236-7239$ & // & / / & Unknown \\
\hline $12-13$ & $7241-7242$ & // & / 1 & Unknown \\
\hline 14 & 7258 & Pakistan, 1984 & / / & Parachinar \\
\hline 15 & 7260 & // & // & Kurrum Agency \\
\hline $16-18$ & $7261-7263$ & // & / / & Pachinar \\
\hline 19 & 7268 & // & / / & Parachinar \\
\hline 20 & 7269 & // & / / & Unknown \\
\hline 21 & 7271 & // & // & Unknown \\
\hline 22 & 7280 & // & // & Unknown \\
\hline 23 & 7281 & Pakistan, 1987 & // & Mansehra \\
\hline $24-29$ & 7284-89 & Pakistan, 1984 & // & Chitral \\
\hline $30-35$ & $7290-7295$ & / / & // & Swat \\
\hline $36-39$ & 7296-99 & // & // & Mansehra \\
\hline 40 & 7396 & Pakistan, 1987 & // & // \\
\hline 41 & 7397 & // & / / & Swat \\
\hline 42 & 7411 & // & Unknown & Unknown \\
\hline 43 & 7413 & // & // & // \\
\hline 44 & 7414 & // & // & // \\
\hline 45 & 7416 & // & // & // \\
\hline $46-47$ & $7418-7419$ & // & // & // \\
\hline 48 & 7420 & // & Gilgit, Baltistan & NA \\
\hline $49-51$ & $7593-7595$ & // & Khyber Pakhtunkhwa & Malakand \\
\hline $52-55$ & $7597-7600$ & // & // & // \\
\hline 56 & 7601 & Pakistan, 1989 & // & Dir \\
\hline $57-64$ & $7603-7610$ & // & // & // \\
\hline $63-84$ & $7611-7630$ & // & // & Chitral \\
\hline $85-93$ & $7632-7640$ & // & // & Swat \\
\hline 94 & 7641 & // & // & Unknown \\
\hline 95-104 & $7648-7657$ & // & // & Mansehra \\
\hline 105-106 & $7672-7673$ & // & Punjab & Gujrat \\
\hline 107-108 & $7734-7735$ & // & AJK & NA \\
\hline $109-110$ & $7737-7738$ & // & Khyber Pakhtunkhwa & Unknown \\
\hline $111-113$ & $7753-7755$ & // & / / & Besham \\
\hline 114 & 7756 & // & // & Unknown \\
\hline 115 & 7759 & // & / / & Mansehra \\
\hline 116 & 7760 & // & / / & Unknown \\
\hline 117 & 7762 & // & // & // \\
\hline 118 & 7763 & // & Punjab & Gujranwala \\
\hline 119 & 7765 & // & // & Bahawalnagar \\
\hline 120 & 7766 & // & // & Bahawalpur \\
\hline
\end{tabular}


Table 1. Cont.

\begin{tabular}{|c|c|c|c|c|}
\hline S. No & Accession No. & Country, Year of Release & $\begin{array}{c}\text { Province/ } \\
\text { Donor No/Area }\end{array}$ & District \\
\hline $121-147$ & $7783-7809$ & Pakistan, 1991 & Khyber Pakhtunkhwa & Chitral \\
\hline $148-155$ & $7811-7818$ & // & // & // \\
\hline $156-159$ & $7819-7822$ & // & // & // \\
\hline $160-163$ & $7824-7827$ & // & / / & // \\
\hline $164-166$ & $7828-7830$ & // & // & Unknown \\
\hline $167-169$ & $7831-7833$ & // & // & // \\
\hline 170 & 7836 & // & // & // \\
\hline 171 & 7839 & // & // & Unknown \\
\hline 172 & 7847 & Pakistan, 1973 & RGP-ARC & NA \\
\hline 173 & 7850 & // & // & // \\
\hline 174 & 7859 & // & // & // \\
\hline 175 & 7863 & // & // & // \\
\hline $176-177$ & $7864-7865$ & Pakistan, 1972 & // & // \\
\hline 178 & 7869 & Pakistan, 1973 & // & / / \\
\hline 179 & 7883 & // & // & // \\
\hline 180 & 7886 & // & // & // \\
\hline 181 & 7937 & Pakistan,1991 & // & Chitral \\
\hline 182 & 8083 & // & // & // \\
\hline 183 & 8085 & // & // & // \\
\hline 184 & 17940 & // & // & Swat \\
\hline $185-186$ & $17,941-17,942$ & Pakistan, 2000 & // & Nowshehra \\
\hline 187-189 & $17,943-17,945$ & Pakistan, 1996 & // & Chitral \\
\hline 190 & 17,946 & Pakistan, 1997 & // & Mansehra \\
\hline 191-202 & $17,947-17,958$ & IRRI, 1999 & NA & NA \\
\hline 203 & 18,231 & \multicolumn{3}{|c|}{ Source not mentioned in the catalog } \\
\hline 204 & 23,718 & \multicolumn{3}{|c|}{ // } \\
\hline 205-206 & $23,727-23,728$ & \multicolumn{3}{|c|}{ // } \\
\hline 207-208 & $23,731-23,732$ & \multicolumn{3}{|c|}{ // } \\
\hline 209 & 23,736 & \multicolumn{3}{|c|}{ // } \\
\hline 210 & 23,744 & & & \\
\hline 211 & Boti & Pakistan & Khyber, Pakhtunkhwa & Swat \\
\hline 212 & Fakhre Malakand & // & // & Malakand \\
\hline $213-217$ & Five Transgenic seeds & NA & NA & NA \\
\hline
\end{tabular}

\subsection{Extraction of Lectins from Rice}

The dry, mature seeds were finely grounded in a mortar and pestle. Seed meal was defatted with two volumes of hexane twice by centrifugation, and then dried overnight at room temperature [38]. About $0.2 \mathrm{~g}$ of defatted seed flour was added to $1 \mathrm{~mL}$ of $1 \mathrm{X}$ phosphate buffer saline (PBS; $137 \mathrm{mM} \mathrm{NaCl}, 2.7 \mathrm{mM} \mathrm{KCl}, 10 \mathrm{mM} \mathrm{Na} \mathrm{HPO}_{4}$, and $1.8 \mathrm{mM} \mathrm{KH}_{2} \mathrm{PO}_{4}, \mathrm{pH} 7.4$ ), shaken for $4 \mathrm{~h}$ on an orbital shaker before centrifugation. The suspension was then cleared by centrifugation at $10,000 \times g$ for $10 \mathrm{~min}$ at $4{ }^{\circ} \mathrm{C}$, and the extract was stored at $-20{ }^{\circ} \mathrm{C}[21]$.

\subsection{Preparation of $R B C s$}

About $2 \mathrm{~mL}$ of Californian breed rabbit blood was obtained in ethylene diamine tetraacetic acid (EDTA) tubes from animal husbandry of Agriculture University Peshawar Khyber Pakhtunkhwa, Pakistan.It was immediately centrifuged at $2000 \mathrm{rpm}$ for $10 \mathrm{~min}$. The serum was discarded, and the pellet was washed twice with 1 X PBS. Finally, the washed erythrocytes were suspended in 1 X PBS at a concentration of $5 \%$ in different flasks and used for HA [33].

\subsection{HA Assay}

The assay was carried out in a standard U-bottomed microplate. The accessions showing the highest agglutination were serially diluted 2-fold as Bing et al. described [34]. A $50 \mu \mathrm{L}$ of the clarified lectin extract was mixed with half volume $(25 \mu \mathrm{L})$ of $5 \%$ Californian breed rabbit erythrocytes and incubated for $30 \mathrm{~min}$ at room temperature. HA was observed with the naked eye, measured titer, representing reciprocal of highest dilution upon which 
full agglutination was achieved. The specific activity of HA is defined as the titer of HA per mg of protein [21,39].

\subsection{Total Protein Estimation}

A standard but miniaturized photometric Bradford method was used to estimate the protein content in the seed extracts having BSA as standard using a 96 welled U-bottomed microplate via reader at 595nm [40,41]. The detailed method is given in Table 2.

Table 2. Method of two-fold serial dilution, corresponding titer values, HA units/mL, and specific activity.

\begin{tabular}{|c|c|c|c|c|c|}
\hline Dilution Number & $\begin{array}{c}\text { Ratio and \%Age } \\
\text { Concentration of the } \\
\text { Diluted Sample }\end{array}$ & \multicolumn{2}{|c|}{ Dilution Factor } & $\begin{array}{c}\text { HA Titer Value } \\
\text { (HU/mL) }\end{array}$ & $\begin{array}{c}\text { Specific } \\
\text { Activity = Titre/mg of } \\
\text { Protein }\end{array}$ \\
\hline Original sample & $1: 1(100 \%)$ & $1 / 2^{0}$ & 1 & 1 & \\
\hline 1 & $1: 2(50 \%)$ & $1 / 2^{1}$ & $1 / 2$ & 2 & \\
\hline 2 & $1: 4(25 \%)$ & $1 / 2^{2}$ & $1 / 4$ & 4 & \\
\hline 3 & $1: 8(12.5 \%)$ & $1 / 2^{3}$ & $1 / 8$ & 8 & e.g., Protein \\
\hline 4 & $1: 16(0.063 \%)$ & $1 / 2^{4}$ & $1 / 16$ & 16 & Concentration $=6.2 \mathrm{mg} / \mathrm{mL}$ \\
\hline 5 & $1: 32(0.0313 \%)$ & $1 / 2^{5}$ & $1 / 32$ & 32 & and titre $=16$ Therefore, \\
\hline 6 & $1: 64(0.01563 \%)$ & $1 / 2^{6}$ & $1 / 64$ & 64 & Specific activity of the \\
\hline 7 & $1: 128(0.007813 \%)$ & $1 / 2^{7}$ & $1 / 128$ & 128 & plant/animal lectins \\
\hline 8 & $1: 256(0.0039063 \%)$ & $1 / 2^{8}$ & $1 / 256$ & 256 & showing visible HA will \\
\hline 9 & $1: 512(0.00195313 \%)$ & $1 / 2^{9}$ & $1 / 512$ & 512 & be $16 / 6.2=2.58$ \\
\hline 10 & $1: 1024(0.0009766 \%)$ & $1 / 2^{10}$ & $1 / 1024$ & 1024 & \\
\hline 11 & 1:2048 (0.0004883\%) & $1 / 2^{11}$ & $1 / 2048$ & 2048 & \\
\hline 12 & $1: 4096(0.000244141 \%)$ & $1 / 2^{12}$ & $1 / 4096$ & 4096 & \\
\hline
\end{tabular}

The percentage concentration of the diluted sample is calculated as a ratio multiplied by 100. Reciprocal of highest dilution showing visible agglutination.

\subsection{Hemagglutination Inhibition Assay (HIA)}

Hemagglutination inhibition assay (HAI or $\mathrm{HI}$ ) using D-Glucose was performed as described by Adenike and Ereton, (2004) [42]. Serial dilutions of the carbohydrate solution (D-Glucose; initial concentration $200 \mathrm{mM}$ ) were incubated at room temperature with equal volume of the lectin extract for $30 \mathrm{~min}$. After that $50 \mu \mathrm{L}$ of $5 \%$ rabbit erythrocytes were added, mixed, and incubated for further $30 \mathrm{~min}$.

\subsection{Screening Blood Affinity for Rice Lectins}

The affinity of different blood types with rice lectins was screened using various percentages (3-5\%) of erythrocytes obtained from various sources, including human (blood group $\mathrm{B}+$ ), broiler chicken, and two strains of rabbit, i.e., local and Californian breed rabbit $[20,42]$.

\section{Results}

\subsection{Rice Lectins Extraction}

The results of lectins extraction from rice for the analysis are given in Tables 3 and 4 . The procedure of lectin assay was miniaturized as a large number of samples (i.e., 217) of rice (Oryza sativa L.) had to be analyzed; also, the plant material available was less in quantity (5-10 seeds). Thus 96-welled microplate was used for HA.

Table 3. Hemagglutination activity (HA) with Californian breed rabbit RBCs and protein content (mg/mL) in the seeds of rice (Oryza sativa L.) accessions using Bradford method.

\begin{tabular}{|c|c|c|c|c|c|c|c|c|c|c|c|c|c|c|c|}
\hline $\begin{array}{c}\text { S. } \\
\text { No }\end{array}$ & $\begin{array}{l}\text { Acce- } \\
\text { ssion } \\
\text { No. }\end{array}$ & HA & $\begin{array}{c}\text { Protein } \\
\text { Conc. } \\
\mathrm{mg} / \mathrm{mL}\end{array}$ & $\begin{array}{c}\text { S. } \\
\text { No }\end{array}$ & $\begin{array}{c}\text { Acce- } \\
\text { ssion } \\
\text { No. }\end{array}$ & HA & $\begin{array}{l}\text { Protein } \\
\text { Conc. } \\
\text { mg/mL }\end{array}$ & $\begin{array}{c}\text { S. } \\
\text { No }\end{array}$ & $\begin{array}{l}\text { Acce- } \\
\text { ssion } \\
\text { No. }\end{array}$ & HA & $\begin{array}{l}\text { Protein } \\
\text { Conc. } \\
\mathrm{mg} / \mathrm{mL}\end{array}$ & $\begin{array}{c}\text { S. } \\
\text { No }\end{array}$ & $\begin{array}{l}\text { Acce- } \\
\text { ssion } \\
\text { No. }\end{array}$ & HA & $\begin{array}{c}\text { Protein } \\
\text { Conc. } \\
\text { mg/mL }\end{array}$ \\
\hline 1 & 7216 & + & 5.815 & 54 & 7599 & + & 5.38 & 107 & 7734 & $t^{3}$ & 4.269 & 160 & 7822 & $t^{3}$ & 6.425 \\
\hline 2 & 7217 & + & 5.18 & 55 & 7600 & + & 8.03 & 108 & 7735 & $t^{2}$ & 4.808 & 161 & 7824 & + & 4.608 \\
\hline 3 & 7218 & + & 5.865 & 56 & 7601 & + & 6.33 & 109 & 7736 & + & 6.245 & 162 & 7825 & $t^{2}$ & 6.545 \\
\hline 4 & 7219 & + & 5.77 & 57 & 7603 & + & 5.67 & 110 & 7737 & $t^{2}$ & 4.931 & 163 & 7826 & + & 6.785 \\
\hline 5 & 7225 & - & 7.3 & 58 & 7604 & + & 4.994 & 111 & 7738 & + & 4.998 & 164 & 7827 & $t^{2}$ & 4.956 \\
\hline
\end{tabular}


Table 3. Cont.

\begin{tabular}{|c|c|c|c|c|c|c|c|c|c|c|c|c|c|c|c|}
\hline $\begin{array}{l}\text { S. } \\
\text { No }\end{array}$ & $\begin{array}{l}\text { Acce- } \\
\text { ssion } \\
\text { No. }\end{array}$ & HA & $\begin{array}{l}\text { Protein } \\
\text { Conc. } \\
\mathrm{mg} / \mathrm{mL}\end{array}$ & $\begin{array}{c}\text { S. } \\
\text { No }\end{array}$ & $\begin{array}{c}\text { Acce- } \\
\text { ssion } \\
\text { No. }\end{array}$ & HA & $\begin{array}{l}\text { Protein } \\
\text { Conc. } \\
\mathrm{mg} / \mathrm{mL}\end{array}$ & $\begin{array}{l}\text { S. } \\
\text { No }\end{array}$ & $\begin{array}{c}\text { Acce- } \\
\text { ssion } \\
\text { No. }\end{array}$ & HA & $\begin{array}{l}\text { Protein } \\
\text { Conc. } \\
\mathrm{mg} / \mathrm{mL}\end{array}$ & $\begin{array}{c}\text { S. } \\
\text { No }\end{array}$ & $\begin{array}{l}\text { Acce- } \\
\text { ssion } \\
\text { No. }\end{array}$ & HA & $\begin{array}{c}\text { Protein } \\
\text { Conc. } \\
\mathrm{mg} / \mathrm{mL}\end{array}$ \\
\hline 6 & 7234 & + & 4.621 & 59 & 7605 & + & 6.65 & 112 & 7753 & + & 3.056 & 165 & 7828 & $t^{2}$ & 4.897 \\
\hline 7 & 7235 & $t^{3}$ & 4.996 & 60 & 7606 & + & 5.965 & 113 & 7754 & + & 4.703 & 166 & 7829 & $t^{2}$ & 4.672 \\
\hline 8 & 7236 & + & 3.87 & 61 & 7607 & $t^{2}$ & 4.878 & 114 & 7755 & $t^{2}$ & 5.42 & 167 & 7830 & + & 5.125 \\
\hline 9 & 7237 & $+^{2}$ & 4.731 & 62 & 7608 & $t^{2}$ & 5.2 & 115 & 7756 & $t^{3}$ & 5.285 & 168 & 7831 & $+^{3}$ & 5.585 \\
\hline 10 & 7238 & $t^{2}$ & 4.344 & 63 & 7609 & + & 6.25 & 116 & 7759 & $t^{3}$ & 7.84 & 169 & 7832 & + & 4.28 \\
\hline 11 & 7239 & - & 4.293 & 64 & 7610 & + & 6.94 & 117 & 7760 & $t^{3}$ & 4.770 & 170 & 7833 & + & 6.335 \\
\hline 12 & 7241 & + & 4.624 & 65 & 7611 & $t^{3}$ & 6.115 & 118 & 7762 & $t^{3}$ & 5.375 & 171 & 7836 & $t^{3}$ & 5.685 \\
\hline 13 & 7242 & $t^{2}$ & 4.871 & 66 & 7612 & $+^{3}$ & 5.965 & 119 & 7763 & $t^{2}$ & 4.167 & 172 & 7839 & $t^{2}$ & 4.354 \\
\hline 14 & 7258 & $t^{3}$ & 5.735 & 67 & 7613 & $t^{2}$ & 6.575 & 120 & 7765 & + & 4.463 & 173 & 7847 & $t^{2}$ & 4.912 \\
\hline 15 & 7260 & $t^{3}$ & 6.26 & 68 & 7614 & $t^{3}$ & 6.995 & 121 & 7766 & + & 5.155 & 174 & 7850 & + & 4.504 \\
\hline 16 & 7261 & $+^{2}$ & 4.98 & 69 & 7615 & + & 6.665 & 122 & 7783 & + & 6.04 & 175 & 7859 & + & 5.79 \\
\hline 17 & 7262 & $+^{3}$ & 4.326 & 70 & 7616 & $t^{3}$ & 6.82 & 123 & 7784 & + & 4.884 & 176 & 7863 & + & 5.045 \\
\hline 18 & 7263 & + & 3.372 & 71 & 7617 & + & 5.16 & 124 & 7785 & $t^{3}$ & 6.845 & 177 & 7864 & + & 4.197 \\
\hline 19 & 7268 & $t^{3}$ & 4.365 & 72 & 7618 & $t^{3}$ & 6.235 & 125 & 7786 & $t^{3}$ & 6.675 & 178 & 7865 & + & 4.398 \\
\hline 20 & 7269 & $t^{2}$ & 4.706 & 73 & 7619 & $t^{2}$ & 6.465 & 126 & 7787 & + & 6.825 & 179 & 7869 & + & 4.515 \\
\hline 21 & 7271 & $t^{3}$ & 4.326 & 74 & 7620 & $t^{3}$ & 5.3 & 127 & 7788 & $t^{2}$ & 7.13 & 180 & 7883 & + & 4.327 \\
\hline 22 & 7280 & $t^{3}$ & 5.105 & 75 & 7621 & $t^{3}$ & 5.815 & 128 & 7789 & $t^{2}$ & 6.14 & 181 & 7886 & $t^{3}$ & 5.665 \\
\hline 23 & 7281 & + & 5 & 76 & 7622 & $t^{3}$ & 6.305 & 129 & 7790 & $+^{3}$ & 6.815 & 182 & 7937 & + & 5.94 \\
\hline 24 & 7284 & + & 6.165 & 77 & 7623 & + & 4.915 & 130 & 7791 & $t^{3}$ & 7.585 & 183 & 8083 & $+^{3}$ & 6.215 \\
\hline 25 & 7285 & $t^{3}$ & 5.445 & 78 & 7624 & $t^{3}$ & 4.421 & 131 & 7792 & $t^{2}$ & 6.62 & 184 & 8085 & $t^{3}$ & 6.78 \\
\hline 26 & 7286 & $+^{3}$ & 6.95 & 79 & 7625 & $t^{2}$ & 5.755 & 132 & 7793 & $+^{2}$ & 6.8 & 185 & 17940 & $+^{2}$ & 6.765 \\
\hline 27 & 7287 & $+^{3}$ & 6.565 & 80 & 7626 & + & 6.785 & 133 & 7794 & $+^{2}$ & 5.76 & 186 & 17941 & + & 5.51 \\
\hline 28 & 7288 & $+^{3}$ & 6.13 & 81 & 7627 & + & 6.98 & 134 & 7795 & $+^{3}$ & 6.185 & 187 & 17942 & + & 5.54 \\
\hline 29 & 7289 & $+^{3}$ & 6.995 & 82 & 7628 & $t^{3}$ & 5.375 & 135 & 7796 & + & 7.28 & 188 & 17943 & + & 6.055 \\
\hline 30 & 7290 & + & 5.07 & 83 & 7629 & + & 5.6 & 136 & 7797 & $t^{2}$ & 7.56 & 189 & 17944 & + & 4.716 \\
\hline 31 & 7291 & + & 4.418 & 84 & 7630 & + & 6.855 & 137 & 7798 & $t^{3}$ & 7.525 & 190 & 17945 & - & 5.395 \\
\hline 32 & 7292 & $+^{2}$ & 4.037 & 85 & 7632 & + & 6.43 & 138 & 7799 & $t^{3}$ & 7.51 & 191 & 17946 & $t^{2}$ & 6.915 \\
\hline 33 & 7293 & $t^{2}$ & 3.761 & 86 & 7633 & + & 5.1 & 139 & 7800 & $t^{3}$ & 5.765 & 192 & 17947 & + & 5.375 \\
\hline 34 & 7294 & + & 3.929 & 87 & 7634 & $t^{2}$ & 5.315 & 140 & 7801 & + & 3.545 & 193 & 17948 & - & 5.795 \\
\hline 35 & 7295 & + & 4.376 & 88 & 7635 & + & 5.25 & 141 & 7802 & $t^{3}$ & 3.352 & 194 & 17949 & + & 5.515 \\
\hline 36 & 7296 & + & 7.245 & 89 & 7636 & $t^{3}$ & 5.22 & 142 & 7803 & + & 4.465 & 195 & 17951 & + & 5.27 \\
\hline 37 & 7297 & + & 4.712 & 90 & 7637 & $t^{3}$ & 4.695 & 143 & 7804 & $+^{3}$ & 7.29 & 196 & 17952 & + & 4.99 \\
\hline 38 & 7298 & $t^{2}$ & 4.560 & 91 & 7638 & $t^{2}$ & 4.382 & 144 & 7805 & $t^{3}$ & 5.31 & 197 & 17953 & + & 5.755 \\
\hline 39 & 7299 & + & 3.718 & 92 & 7639 & + & 7.16 & 145 & 7806 & $t^{3}$ & 5.505 & 198 & 17954 & + & 4.9185 \\
\hline 40 & 7396 & $t^{3}$ & 7.35 & 93 & 7640 & + & 6.81 & 146 & 7807 & $t^{3}$ & 3.845 & 199 & 17955 & + & 6.26 \\
\hline 41 & 7397 & + & 5.265 & 94 & 7641 & $t^{2}$ & 5.11 & 147 & 7808 & $t^{2}$ & 4.815 & 200 & 17956 & + & 5.875 \\
\hline 42 & 7411 & $t^{3}$ & 6.26 & 95 & 7648 & + & 4.913 & 148 & 7809 & $t^{3}$ & 6.081 & 201 & 17957 & + & 5.38 \\
\hline 43 & 7413 & $+^{3}$ & 5.1 & 96 & 7649 & + & 5.175 & 149 & 7811 & $t^{3}$ & 4.56 & 202 & 17958 & - & 5.59 \\
\hline 44 & 7414 & $+^{3}$ & 5.65 & 97 & 7650 & + & 4.617 & 150 & 7812 & $t^{3}$ & 5.67 & 203 & 18231 & + & 4.0485 \\
\hline 45 & 7416 & $t^{3}$ & 4.985 & 98 & 7651 & $t^{2}$ & 4.105 & 151 & 7813 & $t^{3}$ & 6.12 & 204 & 23718 & + & 5.68 \\
\hline 46 & 7418 & $+^{3}$ & 5.4 & 99 & 7652 & $t^{2}$ & 4.565 & 152 & 7814 & $t^{3}$ & 4.84 & 205 & 23727 & + & 5.575 \\
\hline 47 & 7419 & $+^{3}$ & 6 & 100 & 7653 & $t^{2}$ & 5.78 & 153 & 7815 & $t^{3}$ & 4.495 & 206 & 23728 & $+^{2}$ & 5.66 \\
\hline 48 & 7420 & $+^{3}$ & 5.63 & 101 & 7654 & + & 6.785 & 154 & 7816 & $+^{2}$ & 4.315 & 207 & 23731 & $+^{2}$ & 3.577 \\
\hline 49 & 7593 & + & 4.168 & 102 & 7655 & + & 5.63 & 155 & 7817 & $t^{3}$ & 6.31 & 208 & 23732 & $t^{3}$ & 3.8585 \\
\hline 50 & 7594 & + & 7.5 & 103 & 7656 & + & 7.335 & 156 & 7818 & + & 4.39 & 209 & 23736 & $++^{3}$ & 6.22 \\
\hline 51 & 7595 & + & 4.522 & 104 & 7657 & + & 6.23 & 157 & 7819 & $t^{3}$ & 7.07 & 210 & 23744 & + & 3.6395 \\
\hline 52 & 7597 & + & 4.579 & 105 & 7672 & $t^{2}$ & 4.114 & 158 & 7820 & $t^{3}$ & 5.64 & 211 & Boti & $+^{2}$ & . \\
\hline \multirow{2}{*}{53} & 7598 & + & 5.29 & 106 & 7673 & + & 4.958 & 159 & 7821 & $+^{2}$ & 6.56 & 212 & F.M & $t^{2}$ & 2.79 \\
\hline & & & $7=$ Five & ansge & seeds c & & re only & & & & vith 3.5 & nd 3.7 & toin & & \\
\hline
\end{tabular}

The hemagglutination (HA) results of 217rice (Oryza sativa L.) genotypes; accessions (210), local varieties (02) and transgenic seeds (05) showing weak $(+)$, high $\left(++/+^{2}\right)$, highest $\left(+++/+^{3}\right)$ and negative $(-)$, using $5 \%$ Californian breed rabbit RBCs provided by IABGR/ NARC Islamabad. Above values of protein concentration are $\mathrm{mg} / 100 \mathrm{mg}$ of rice flour. Protein contents were measured via microplate reader at $595 \mathrm{~nm}$ using Bradford reagent and the difference of $( \pm 0.4)$ was noted between the values of protein concentration. $(\ldots \ldots)$ represent (missing value); Boti \& F.M (Fakhre Malakand) are local varieties.

Table 4. HA, protein content $(\mathrm{mg} / \mathrm{mL})$, titer values, and specific activity in the seeds of 106 rice (Oryza sativa L.) accessions.

\begin{tabular}{|c|c|c|c|c|c|c|c|c|c|c|c|c|c|c|c|c|c|}
\hline $\begin{array}{l}\text { S. } \\
\text { No }\end{array}$ & $\begin{array}{l}\text { Acce- } \\
\text { ssion } \\
\text { No. }\end{array}$ & HA & $\begin{array}{l}\text { Protein } \\
\text { Conc. } \\
\mathrm{mg} / \mathrm{mL}\end{array}$ & $\begin{array}{c}\text { Titre } \\
\text { Value }\end{array}$ & $\begin{array}{l}\text { Specific } \\
\text { Activity } \\
\text { HU/mg }\end{array}$ & $\begin{array}{c}\text { S. } \\
\text { No }\end{array}$ & $\begin{array}{l}\text { Acce- } \\
\text { ssion } \\
\text { No. }\end{array}$ & HA & $\begin{array}{l}\text { Protein } \\
\text { Conc. } \\
\mathrm{mg} / \mathrm{mL}\end{array}$ & $\begin{array}{c}\text { Titer } \\
\text { Value }\end{array}$ & $\begin{array}{l}\text { Specific } \\
\text { Activity } \\
\text { HU/mg }\end{array}$ & $\begin{array}{c}\text { S. } \\
\text { No }\end{array}$ & $\begin{array}{l}\text { Acce- } \\
\text { ssion } \\
\text { No. }\end{array}$ & HA & $\begin{array}{l}\text { Protein } \\
\text { Conc. } \\
\mathrm{mg} / \mathrm{mL}\end{array}$ & $\begin{array}{c}\text { Titre } \\
\text { Value }\end{array}$ & $\begin{array}{l}\text { Specific } \\
\text { Activity } \\
\text { HU/mg }\end{array}$ \\
\hline 1 & 7235 & $t^{3}$ & 4.996 & $2^{7}=128$ & 25.621 & 37 & 7619 & $+^{2}$ & 6.465 & $2^{3}=8$ & 1.237 & 73 & 7800 & $t^{3}$ & 5.765 & $2^{2}=4$ & 0.693 \\
\hline 2 & 7236 & $t^{2}$ & 3.87 & $2^{5}=32$ & 8.268 & 38 & 7620 & $t^{3}$ & 5.3 & $2^{5}=32$ & 6.037 & 74 & 7802 & $t^{3}$ & 3.352 & $2^{3}=8$ & 2.386 \\
\hline 3 & 7237 & $t^{2}$ & 4.731 & $2^{7}=128$ & 27.055 & 39 & 7622 & $t^{3}$ & 6.305 & $2^{3}=8$ & 1.268 & 75 & 7804 & $t^{3}$ & 7.29 & $2^{3}=8$ & 1.097 \\
\hline 4 & 7238 & $t^{2}$ & 4.34 & $2^{7}=128$ & 29.49 & 40 & 7624 & $t^{3}$ & 4.4205 & $2^{4}=16$ & 3.6195 & 76 & 7805 & $t^{3}$ & 5.31 & $2^{2}=4$ & 0.753 \\
\hline 5 & 7242 & $t^{2}$ & 4.871 & $2^{7}=128$ & 26.28 & 41 & 7625 & $+^{2}$ & 5.755 & $2^{2}=4$ & 0.695 & 77 & 7806 & $t^{3}$ & 5.505 & $2^{3}=8$ & 1.453 \\
\hline
\end{tabular}


Table 4. Cont.

\begin{tabular}{|c|c|c|c|c|c|c|c|c|c|c|c|c|c|c|c|c|c|}
\hline $\begin{array}{l}\text { S. } \\
\text { No }\end{array}$ & $\begin{array}{l}\text { Acce- } \\
\text { ssion } \\
\text { No. }\end{array}$ & HA & $\begin{array}{l}\text { Protein } \\
\text { Conc. } \\
\mathrm{mg} / \mathrm{mL}\end{array}$ & $\begin{array}{c}\text { Titre } \\
\text { Value }\end{array}$ & $\begin{array}{l}\text { Specific } \\
\text { Activity } \\
\text { HU/mg }\end{array}$ & $\begin{array}{c}\text { S. } \\
\text { No }\end{array}$ & $\begin{array}{l}\text { Acce- } \\
\text { ssion } \\
\text { No. }\end{array}$ & HA & $\begin{array}{l}\text { Protein } \\
\text { Conc. } \\
\mathrm{mg} / \mathrm{mL}\end{array}$ & $\begin{array}{c}\text { Titer } \\
\text { Value }\end{array}$ & $\begin{array}{l}\text { Specific } \\
\text { Activity } \\
\text { HU/mg }\end{array}$ & $\begin{array}{l}\text { S. } \\
\text { No }\end{array}$ & $\begin{array}{l}\text { Acce- } \\
\text { ssion } \\
\text { No. }\end{array}$ & HA & $\begin{array}{l}\text { Protein } \\
\text { Conc. } \\
\text { mg/mL }\end{array}$ & $\begin{array}{c}\text { Titre } \\
\text { Value }\end{array}$ & $\begin{array}{l}\text { Specific } \\
\text { Activity } \\
\text { HU/mg }\end{array}$ \\
\hline 6 & 7258 & $t^{3}$ & 5.735 & $2^{8}=256$ & 44.63 & 42 & 7627 & + & 6.98 & $2^{1}=2$ & 0.286 & 78 & 7807 & $t^{3}$ & 3.845 & $2^{3}=8$ & 2.081 \\
\hline 7 & 7260 & $t^{3}$ & 6.26 & $2^{2}=4$ & 0.638 & 43 & 7628 & $t^{3}$ & 5.375 & $2^{9}=512$ & 95.25 & 79 & 7808 & $t^{2}$ & 4.815 & $2^{2}=4$ & 0.8307 \\
\hline 8 & 7261 & $t^{2}$ & 4.98 & $2^{2}=4$ & 0.803 & 44 & 7634 & $t^{2}$ & 5.315 & $2^{2}=4$ & 0.752 & 80 & 7809 & $t^{3}$ & 6.08 & $2^{1}=2$ & 0.3289 \\
\hline 9 & 7262 & $t^{3}$ & 2.163 & $2^{2}=4$ & 1.849 & 45 & 7636 & $t^{3}$ & 5.22 & $2^{4}=16$ & 3.065 & 81 & 7811 & $t^{3}$ & 4.56 & $2^{3}=8$ & 1.754 \\
\hline 10 & 7268 & $t^{3}$ & 4.365 & $2^{3}=8$ & 1.8328 & 46 & 7637 & $t^{3}$ & 4.695 & $2^{4}=16$ & 3.407 & 82 & 7812 & $t^{3}$ & 5.67 & $2^{3}=8$ & 1.411 \\
\hline 11 & 7269 & $t^{2}$ & 4.706 & $2^{2}=4$ & 0.8499 & 47 & 7641 & $+^{2}$ & 5.11 & $2^{4}=16$ & 3.131 & 83 & 7813 & $t^{3}$ & 6.12 & $2^{2}=4$ & 0.654 \\
\hline 12 & 7271 & $t^{3}$ & 4.326 & $2^{10}=1024$ & 236.70 & 48 & 7651 & $t^{2}$ & 4.105 & $2^{2}=4$ & 0.974 & 84 & 7814 & $t^{3}$ & 4.84 & $2^{3}=8$ & 1.653 \\
\hline 13 & 7280 & $t^{3}$ & 5.105 & $2^{3}=8$ & 1.5670 & 49 & 7652 & $+^{2}$ & 4.565 & $2^{2}=4$ & 0.876 & 85 & 7815 & $t^{3}$ & 4.495 & $2^{5}=32$ & 7.119 \\
\hline 14 & 7285 & $t^{3}$ & 5.445 & $2^{3}=8$ & 1.469 & 50 & 7655 & + & 5.63 & $2^{8}=256$ & 45.47 & 86 & 7816 & $t^{2}$ & 4.315 & $2^{0}=1$ & 0.231 \\
\hline 15 & 7286 & $t^{3}$ & 6.95 & $2^{3}=8$ & 1.151 & 51 & 7672 & $t^{2}$ & 4.114 & $2^{2}=4$ & 0.972 & 87 & 7819 & $t^{3}$ & 7.07 & $2^{3}=8$ & 1.1315 \\
\hline 16 & 7287 & $t^{3}$ & 6.565 & $2^{3}=8$ & 1.2185 & 52 & 7735 & $t^{2}$ & 4.8085 & $2^{6}=64$ & 13.309 & 88 & 7820 & $t^{3}$ & 5.64 & $2^{4}=16$ & 2.8368 \\
\hline 17 & 7288 & $t^{3}$ & 6.13 & $2^{3}=8$ & 1.3050 & 53 & 7737 & $t^{2}$ & 4.9315 & $2^{7}=128$ & 25.955 & 89 & 7821 & $t^{2}$ & 6.56 & $2^{2}=4$ & 0.609 \\
\hline 18 & 7289 & $t^{3}$ & 6.995 & $2^{3}=8$ & 1.1436 & 54 & 7755 & $+^{2}$ & 5.42 & $2^{5}=32$ & 5.9040 & 90 & 7822 & $t^{3}$ & 6.425 & $2^{3}=8$ & 1.245 \\
\hline 19 & 7292 & $t^{2}$ & 4.0375 & $2^{7}=128$ & 31.702 & 55 & 7756 & $+^{3}$ & 5.285 & $2^{2}=4$ & 0.7568 & 91 & 7825 & $t^{2}$ & 6.545 & $2^{4}=16$ & 2.444 \\
\hline 20 & 7293 & $t^{2}$ & 3.761 & $2^{2}=4$ & 1.0635 & 56 & 7759 & $+^{3}$ & 5.2266 & $2^{3}=8$ & 1.2374 & 92 & 7827 & $t^{2}$ & 4.956 & $2^{5}=32$ & 6.456 \\
\hline 21 & 7298 & $+^{2}$ & 4.5605 & $2^{7}=128$ & 28.067 & 57 & 7760 & $+^{3}$ & 3.1803 & $2^{5}=32$ & 10.07 & 93 & 7828 & $+^{2}$ & 4.897 & $2^{5}=32$ & 6.5346 \\
\hline 22 & 7396 & $+^{3}$ & 7.35 & $2^{2}=4$ & 0.5442 & 58 & 7762 & $+^{3}$ & 3.5833 & $2^{1}=2$ & 0.558 & 94 & 7829 & $+^{2}$ & 4.672 & $2^{6}=64$ & 13.698 \\
\hline 23 & 7411 & $t^{3}$ & 6.26 & $2^{10}=1024$ & 163.57 & 59 & 7763 & $t^{3}$ & 2.7783 & $2^{2}=4$ & 1.4397 & 95 & 7831 & $t^{3}$ & 5.585 & $2^{10}=1024$ & 183.34 \\
\hline 24 & 7413 & $t^{3}$ & 5.1 & $2^{3}=8$ & 1.5686 & 60 & 7785 & $t^{3}$ & 4.5633 & $2^{4}=16$ & 3.506 & 96 & 7836 & $t^{3}$ & 5.685 & $2^{2}=4$ & 0.7036 \\
\hline 25 & 7414 & $t^{3}$ & 5.65 & $2^{3}=8$ & 1.4159 & 61 & 7786 & $t^{3}$ & 4.45 & $2^{3}=8$ & 1.797 & 97 & 7839 & $+t^{2}$ & 4.354 & $2^{2}=4$ & 0.9188 \\
\hline 26 & 7416 & $t^{3}$ & 4.985 & $2^{3}=8$ & 1.6048 & 62 & 7788 & $t^{2}$ & 4.7533 & $2^{8}=256$ & 53.857 & 98 & 7886 & $t^{3}$ & 5.665 & $2^{3}=8$ & 1.412 \\
\hline 27 & 7418 & $t^{3}$ & 5.4 & $2^{4}=16$ & 2.9629 & 63 & 7789 & $t^{2}$ & 4.0933 & $2^{5}=32$ & 7.8176 & 99 & 8083 & $t^{3}$ & 6.215 & $2^{3}=8$ & 1.287 \\
\hline 28 & 7419 & $t^{3}$ & 6 & $2^{10}=1024$ & 170.66 & 64 & 7790 & $t^{3}$ & 4.5433 & $2^{6}=64$ & 14.086 & 100 & 8085 & $t^{3}$ & 6.78 & $2^{9}=512$ & 75.516 \\
\hline 29 & 7607 & $+^{2}$ & 4.8785 & $2^{2}=4$ & 0.8199 & 65 & 7791 & $+^{3}$ & 5.0566 & $2^{3}=8$ & 1.582 & 101 & 17940 & $+^{2}$ & 6.765 & $2^{2}=4$ & 0.591 \\
\hline 30 & 7608 & $t^{2}$ & 5.2 & $2^{2}=4$ & 0.7692 & 66 & 7792 & $t^{2}$ & 4.4133 & $2^{2}=4$ & 0.906 & 102 & 17946 & $t^{2}$ & 6.915 & $2^{1}=2$ & 0.289 \\
\hline 31 & 7611 & $t^{3}$ & 6.115 & $2^{3}=8$ & 1.3082 & 67 & 7793 & $t^{2}$ & 4.5333 & $2^{2}=4$ & 0.882 & 103 & 23728 & $t^{2}$ & 5.66 & $2^{9}=512$ & 90.45 \\
\hline 32 & 7612 & $t^{3}$ & 5.965 & $2^{3}=8$ & 1.3411 & 68 & 7794 & $t^{2}$ & 3.84 & $2^{2}=4$ & 1.0416 & 104 & 23731 & $t^{2}$ & 3.577 & $2^{6}=64$ & 17.89 \\
\hline 33 & 7613 & $t^{2}$ & 6.575 & $2^{3}=8$ & 1.2167 & 69 & 7795 & $t^{3}$ & 4.1233 & $2^{2}=4$ & 0.9700 & 105 & 23732 & $t^{3}$ & 3.859 & $2^{6}=64$ & 16.586 \\
\hline 34 & 7614 & $t^{3}$ & 6.9995 & $2^{4}=16$ & 2.2858 & 70 & 7797 & $t^{2}$ & 5.04 & $2^{0}=1$ & 0.198 & 106 & 23736 & $+^{3}$ & 6.22 & $2^{3}=8$ & 1.286 \\
\hline 35 & 7616 & $+^{3}$ & 6.82 & $2^{3}=8$ & 1.1730 & 71 & 7798 & $+^{3}$ & 5.0166 & $2^{3}=8$ & 1.594 & 107 & F.M & $t^{2}$ & 2.79 & $2^{1}=2$ & 0.71 \\
\hline 36 & 7618 & $t^{3}$ & 6.235 & $2^{3}=8$ & 1.2830 & 72 & 7799 & $t^{3}$ & 5.0066 & $2^{3}=8$ & 1.597 & 108 & 109T.S & $t^{2}$ & $3.54,3.79$ & $2^{1}=2$ & $\begin{array}{l}0.28 \\
0.26\end{array}$ \\
\hline
\end{tabular}

The 109 rice (Oryza sativa L.) genotypes; accessions (106), local varieties (02), transgenic seeds (02), showing the presence of lectins (+) high $(+2 /++)$ or highest $(+3 /+++)$ (HA) results using Californian breed $5 \%$ Rabbit RBCs, were screened further for titer values and specific activity (titer/mg of protein) F.M; Fakhre Malakand, local variety. TS.; transgenic seeds. The above values of protein concentration are $\mathrm{mg} / 100 \mathrm{mg}$ of rice flour. Protein contents were measured via a microplate reader at $595 \mathrm{~nm}$ using the Bradford reagent, and the difference of $( \pm 0.4)$ was noted between the values of protein concentration when multiple readings were taken. Titer values are the reciprocal of the highest two-fold dilution (i.e., $1 / 2 n=2 n$, where $n=0,1,2,3$ ) showing visible agglutination. Specific activity was measured by dividing titer values over the protein content (titer/mg of protein).

\subsection{HA Assay}

Approximately all the accessions showed the presence of lectins via HA out of 217 (210 wild, 2 cultivated and five transgenic) accessions, 109 accessions (106 wild, 1, cultivated, 2 transgenic) gave strong agglutination results (Tables 3 and 4; Figure 1a-g). The accessions (109) exhibiting high HA activity were further serially diluted for titer analysis and specific activity as shown in Table 4 . The respective titer values observed for 7816 and 7271 were 4-1024, making a range of 4.315 (lowest)-1024 (highest) HA unit (HAU) and their specific activity as $0.231-236$. This micro assay requires only 25 to $100 \mu \mathrm{L}$ of extract, whereas the conventional glass slide method requires at least $1000 \mu \mathrm{L}$ of plant extract mixed with the same amount of RBC suspension for a single assay [32,33].

HA is used to detect lectins in the crude or clarified extracts of plants. Purified rice seed extracts were serially diluted by a two-fold dilution method till well\#10. The last wells (11 and 12) were reserved for positive (gum arabic) and blank (PBS).

Figure 1a-g shows most of the accessions' HA assay for lectins using $5 \%$ Californian breed rabbit erythrocytes. The microplate selected for the HA assay was a U-bottomed with 196 wells distributed in 12 columns (from 1-12) and 08 rows (from A-H). Numbering rows as $\mathrm{A}, \mathrm{B}$ and $\mathrm{C}$ etc. in the figures was for convenience to correctly insert the data in the tables below.

Usually, HA is carried out at room temperature, and an equal volume of lectin extract and RBCs suspension is used [21,32,39]. However, this ratio may vary as described in other studies (Zhang et al., 2000) [9]. In this microassay, precise agglutination results were obtained with $25 \mu \mathrm{L}$ of rabbit RBCs mixed with $50 \mu \mathrm{L}$ of rice extract [Figure $1 \mathrm{a}-\mathrm{g}$ ]. For 
accurate and rapid results during cold weather, the microplate can be kept in an incubator instead of room temperature. A visible lattice of RBCs at the bottom of the well was taken as positive and button formation was recorded as negative. The interpretation of HA on a glass slide is different [32]. One of the rules of selection is that the agglutination should settle fast and non-agglutination should settle slowly. Strong positive, weak positive, and intermediate positive were differentiable with the naked eye. In a U-bottom microplate, strong positive samples showed a lattice or network spread throughout the bottom. Diffused button at the bottom showed partial agglutination and sharp button shows negative agglutination results [32,33]. However, these observations and interpretations can vary from lab to lab, expert to expert, type and concentration of RBCs, incubation time, nature of the sample agglutinin, and method of hemagglutination assay [31]. The lectin assay was stable for about $1-2 \mathrm{~h}$, also reported by Zhang et al. [9].

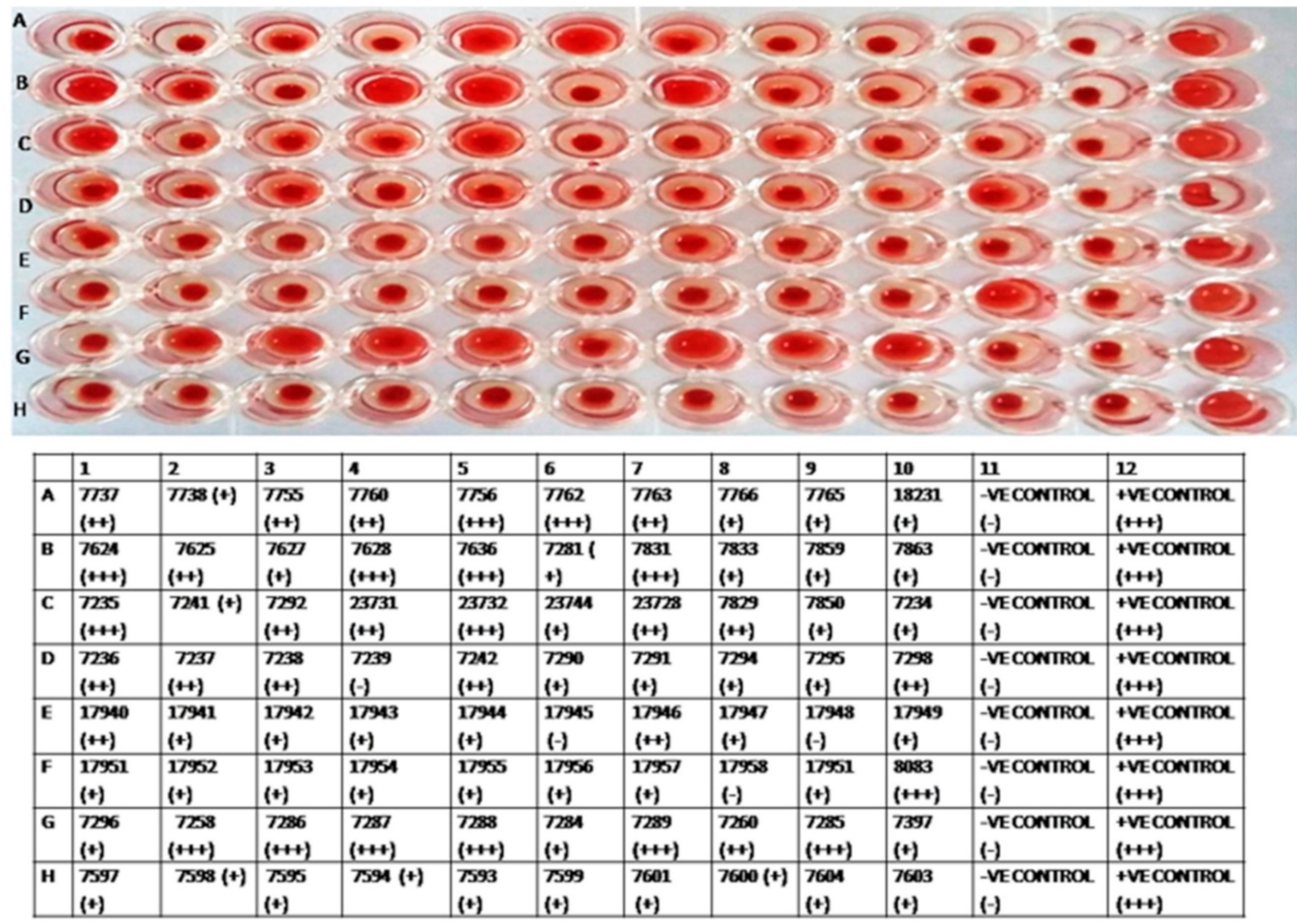

(a)

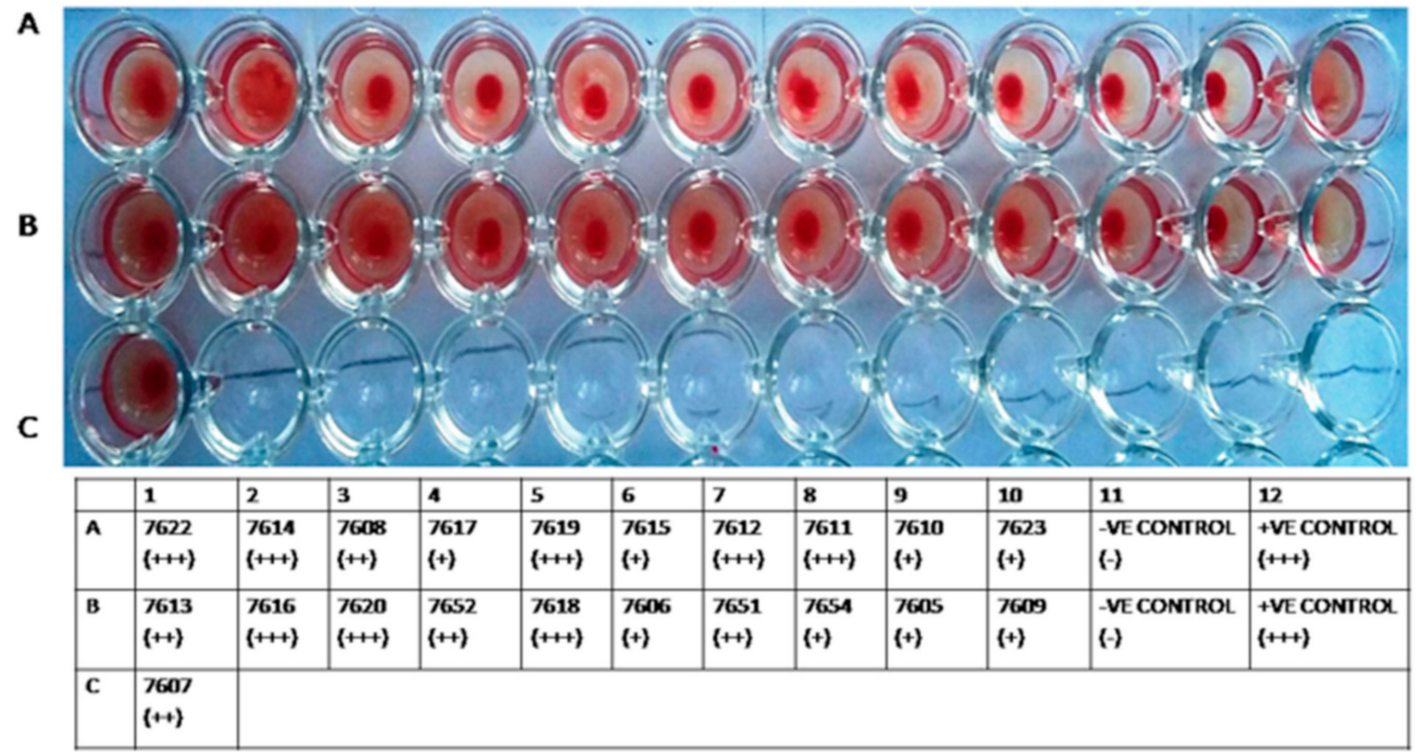

(b)

Figure 1. Cont. 
A

C

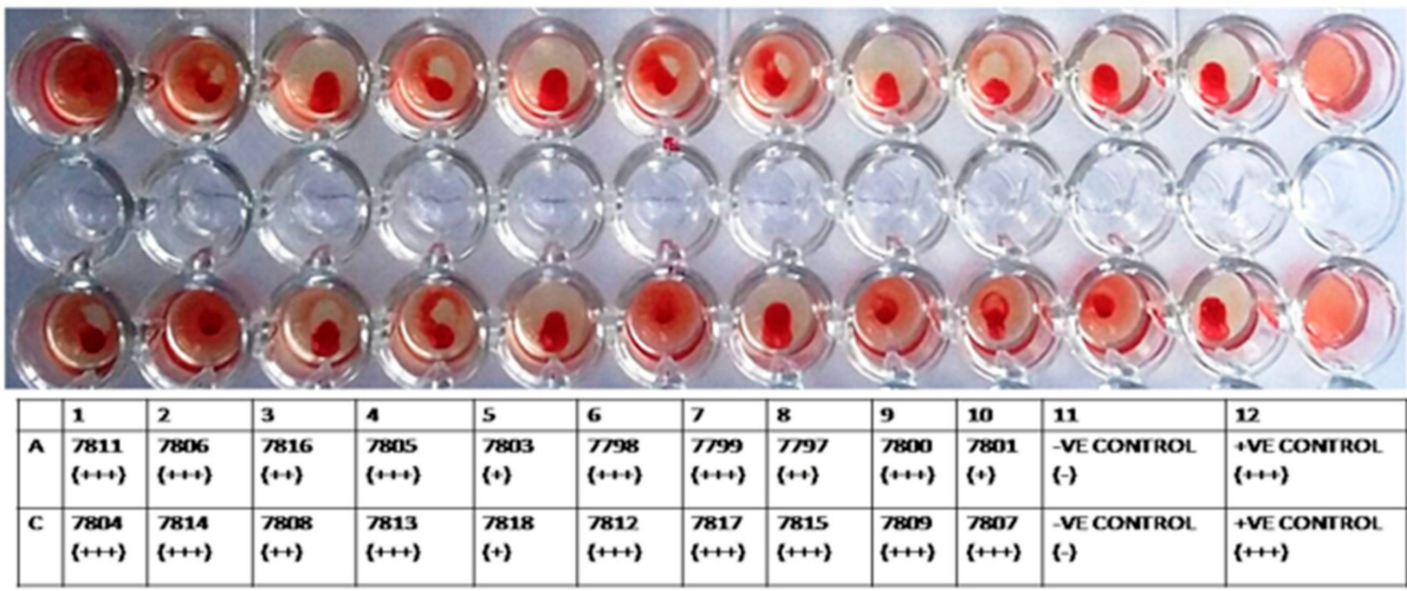

(c)

A

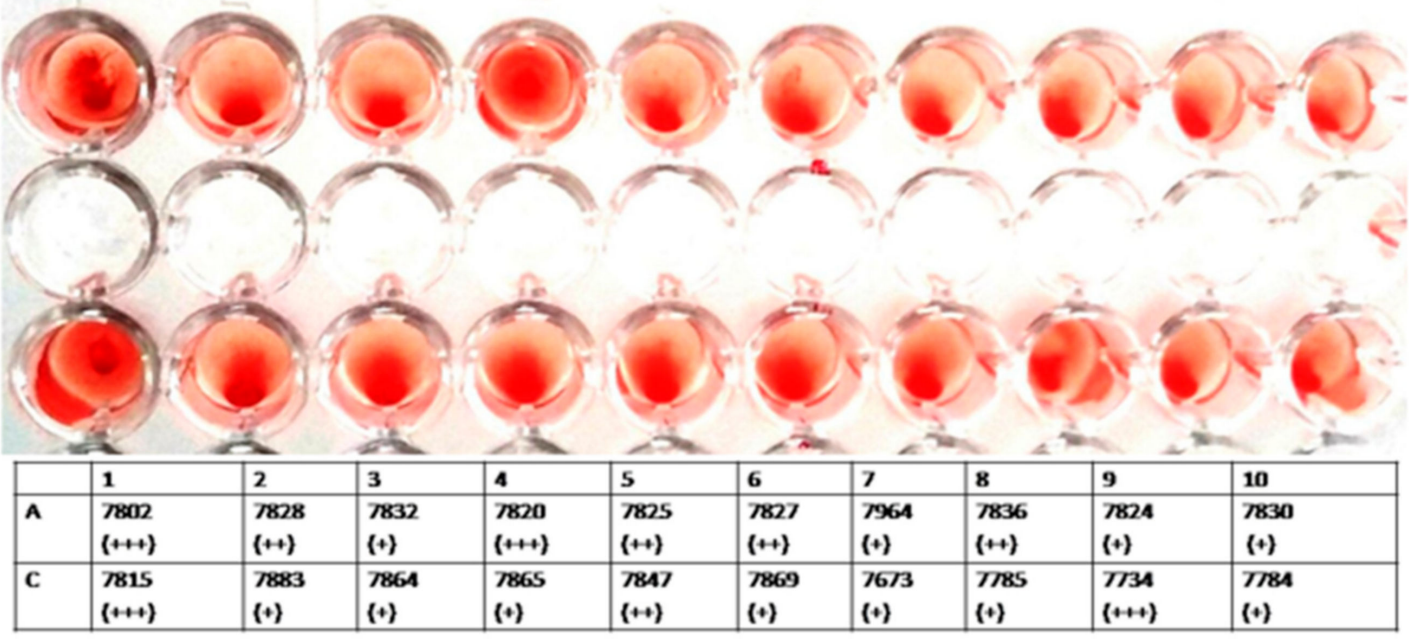

(d)

A

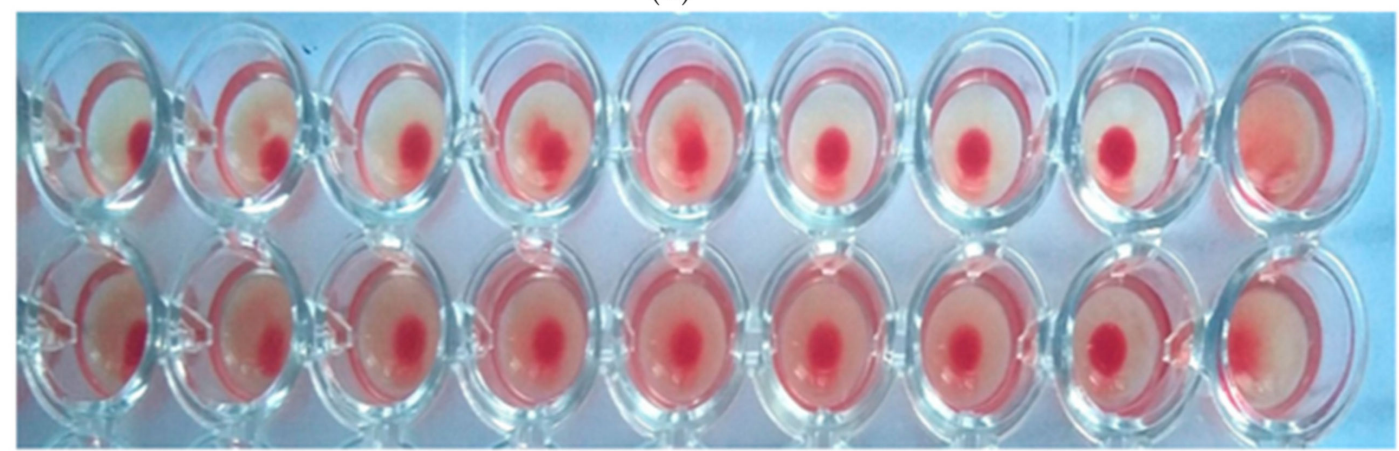

\begin{tabular}{|c|c|c|c|c|c|c|c|c|c|}
\hline & 1 & 2 & 3 & 4 & & 6 & 7 & 8 & \\
\hline A & $\begin{array}{l}7617 \\
(+)\end{array}$ & $\begin{array}{l}7619 \\
(+4)\end{array}$ & $\begin{array}{l}7615 \\
(+)\end{array}$ & $\begin{array}{l}7612 \\
(+1+1)\end{array}$ & $\begin{array}{l}7611 \\
\text { (t+1) }\end{array}$ & $\begin{array}{l}7610 \\
(+)\end{array}$ & $\begin{array}{l}7623 \\
(+)\end{array}$ & $\begin{array}{l}\text {-VEControl } \\
(-)\end{array}$ & $\begin{array}{l}\text { +VEControl } \\
(++1)\end{array}$ \\
\hline$B$ & $\begin{array}{l}7652 \\
(+1)\end{array}$ & $\begin{array}{l}7618 \\
(1+1+1)\end{array}$ & $\begin{array}{l}7606 \\
\text { (4) }\end{array}$ & $\begin{array}{l}7651 \\
(+1)\end{array}$ & $\begin{array}{l}7654 \\
\text { (4) }\end{array}$ & $\begin{array}{l}7605 \\
\text { (4) }\end{array}$ & $\begin{array}{l}7609 \\
(+1)\end{array}$ & $\begin{array}{l}\text {-VEControl } \\
(-)\end{array}$ & $\begin{array}{l}\text { +VEControd } \\
(1+1)\end{array}$ \\
\hline
\end{tabular}

(e)

Figure 1. Cont. 


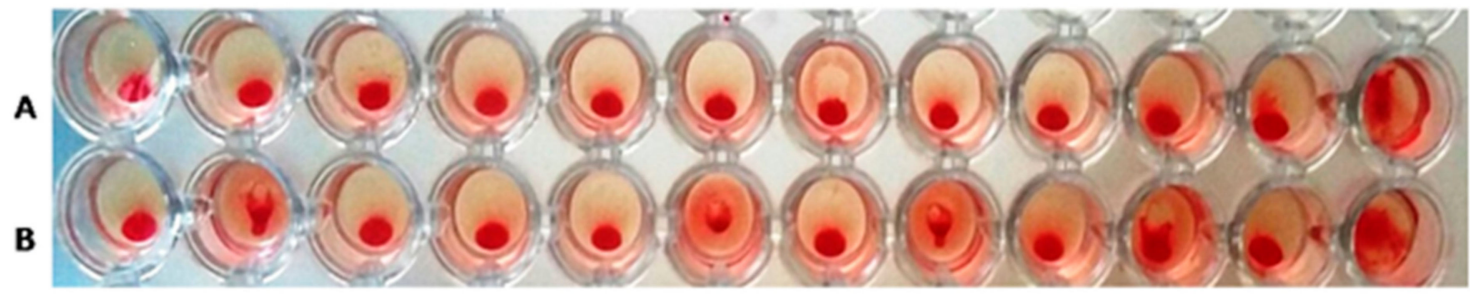

\begin{tabular}{|c|c|c|c|c|c|c|c|c|c|c|c|c|}
\hline & 1 & 2 & 3 & 4 & 5 & 6 & 7 & 8 & 9 & 10 & 11 & 12 \\
\hline A & $\begin{array}{l}7639 \\
(+)\end{array}$ & $\begin{array}{l}7635 \\
(+)\end{array}$ & $\begin{array}{l}7821 \\
(+1)\end{array}$ & $\begin{array}{l}7825 \\
(+1)\end{array}$ & $\begin{array}{l}7824 \\
(+1)\end{array}$ & $\begin{array}{l}7640 \\
(+1)\end{array}$ & $\begin{array}{l}7638 \\
(++1)\end{array}$ & $\begin{array}{l}7626 \\
(+)\end{array}$ & $\begin{array}{l}7826 \\
(+)\end{array}$ & $\begin{array}{l}7648 \\
(+)\end{array}$ & $\begin{array}{l}\text {-VECONTROL } \\
(-)\end{array}$ & $\begin{array}{l}\text { +VECONIROL } \\
(+++)\end{array}$ \\
\hline B & $\begin{array}{l}7650 \\
(+)\end{array}$ & $\begin{array}{l}7820 \\
(+1+1)\end{array}$ & $\begin{array}{l}7632 \\
(+)\end{array}$ & $\begin{array}{l}7649 \\
(+)\end{array}$ & $\begin{array}{l}7633 \\
(+)\end{array}$ & $\begin{array}{l}7819 \\
(+\cdots)\end{array}$ & $\begin{array}{l}7937 \\
(+)\end{array}$ & $\begin{array}{l}7822 \\
(+1+1)\end{array}$ & $\begin{array}{l}7736 \\
(+)\end{array}$ & $\begin{array}{l}7630 \\
(+)\end{array}$ & $\begin{array}{l}\text { - VE CONIROL } \\
(-)\end{array}$ & $\begin{array}{l}\text { +VECONIROL } \\
(+\cdots+1\end{array}$ \\
\hline
\end{tabular}

(f)

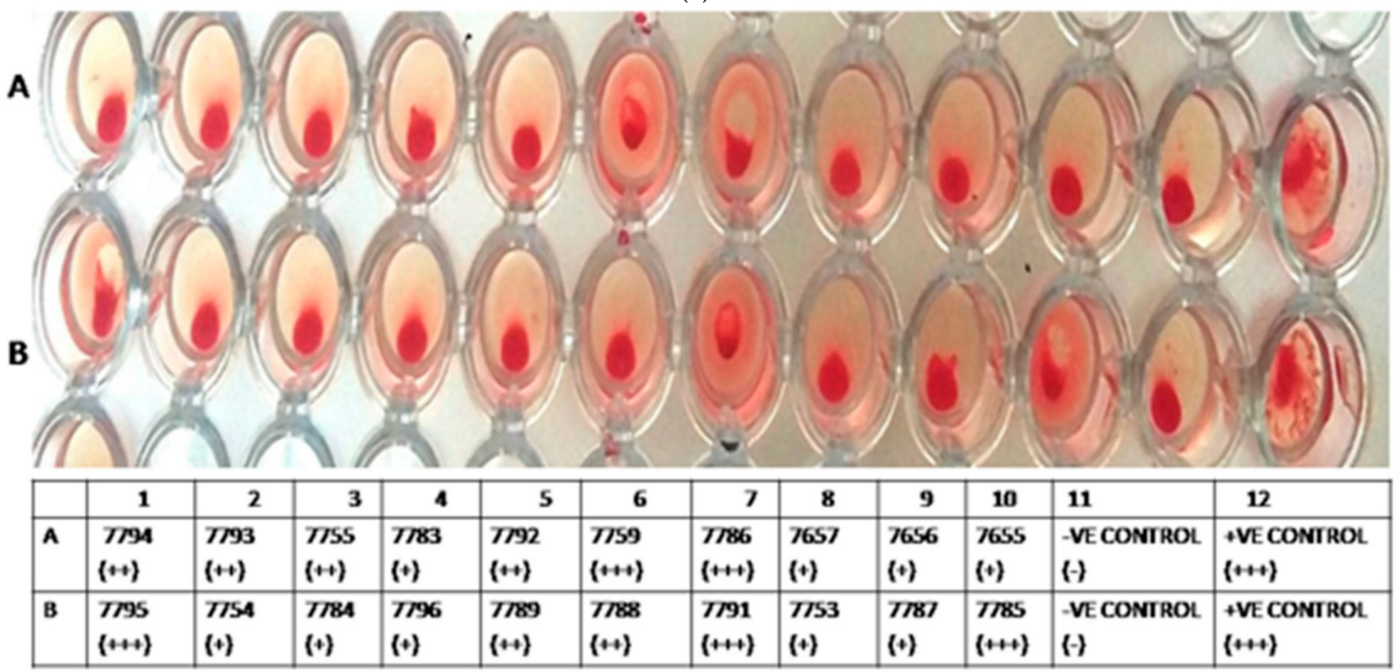

(g)

Figure 1. HA capability of rice (Oryza sativa L.) lectins (a-g) against 5\% Californian breed rabbit RBCs. The + signs are showing HA activity. The HA activities for different rice genotypes are weak $(+)$, high $(++/+2)$, highest $(+++/+3)$ and negative (-), using 5\% Californian breed rabbit RBCs.

\subsection{Total Protein Content}

Results of the protein content determination in the rice accessions are represented in Tables 3 and 4. For all (i.e., 217) of the tested genotypes, a protein concentration of $3-8 \mathrm{mg} / 100 \mathrm{mg}$ of seed flour was observed, the highest among which was $8.03 \mathrm{mg}$ for accession 7600, while the lowest was $3.05 \mathrm{mg}$ for accession 7753 [40]. Sun et al. observed $5-13 \mathrm{~g} / 100 \mathrm{~g}$ of proteins in rice [41].

\section{4. $H A I$}

The rice lectins from all the genotypes were not inhibited by simple monosaccharide (D-glucose) moieties [9]. Other carbohydrates specificity, like mannose and complex polysaccharides needs to be sorted out for these rice accessions. In this study only Dglucose was used, as large number of samples had to be analyzed.

\subsection{Affinity Comparison of Various Types of Blood for Rice Lectins}

HA capability of the rice lectins against different types of blood RBCs was compared with each other as represented in Figure 1. The blood obtained from humans (B+), rabbits (local and Californian breed), and broiler chickens were screened for comparative agglutination results with rice lectins. Californian breed rabbit erythrocytes showed more precise results than human and broiler erythrocytes. However, we have recognized broiler 
chickens as a cheap and readily available source for blood agglutination assays of plant lectins on a large scale (Figure 2). Heard (1955) identified the different blood groups in rabbits and found that some rabbits' red cells are agglutinated more strongly than the red cells of others and to a higher titer. In this study, Californian breed rabbit erythrocytes showed more affinity for rice lectins than local rabbits $[33,35]$.
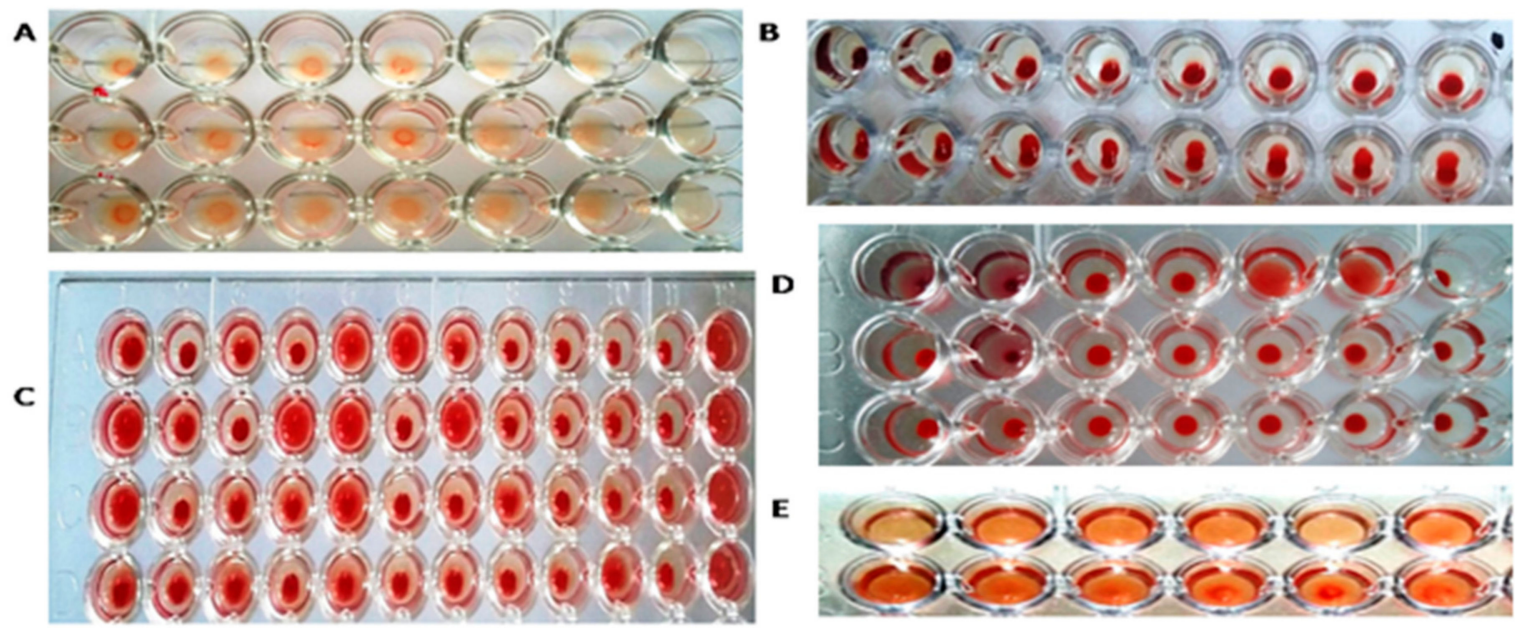

Figure 2. Comparison of rice lectins capability of $\mathrm{HA}$ is shown against $1 \%$ rabbit $\mathrm{RBCs}(\mathrm{A}), 3 \% \mathrm{~B}^{+}$human $\mathrm{RBCs}(\mathrm{B}), 5 \%$ Californian-breed rabbits RBCs (C), 5\% broiler chicken RBCs (D), and 3\% local rabbit RBCs (E).

\section{Discussion}

Identification of stable and resistant genotypes through evaluation of proteins involved in defense is integral for varietal development and release. Plant defense is the primary application of plant lectins in response to biotic and abiotic stresses [10,11]. The study shows that seed storage lectins are present in nearly all 217 rice genotypes (Table 3). A significant highest lectin activity was observed in 109 (i.e., 106 wild) genotypes out of 217 (210 wild), which were further investigated for titer values and specific activity. Twenty-two accessions showed high titer values (ranges 64-1024) and specific activities (ranges 13-170 HU/mg).

The 106 wild accessions of rice (Oryza sativa L.) that exhibited highest agglutination as compared to the rest (210) showed their inherent capability of expressing higher concentration of phytoagglutinins (Table 4). One of the few parameters at molecular level that can easily be used to find the resistant genotypes to biotic and abiotic stresses [16-22]. For semi-quantification of seed lectins in rice a method described in Table 2 was used. The detail of which are given in Table 3. The same method is used for the finding of viral titer [30].

Two local varieties (Fakhre Malakand, Boti) and five transgenic rice varieties were used for the purpose of comparison with the wild relatives. We have found a considerable higher protein concentration, titer values and specific activity in wild accessions of rice as compared to the cultivated and transgenic ones, depicting greater genetic diversity of seed storage lectins [Tables 3 and 4 ].

HA experiments were carried out at room temperature, i.e., $25^{\circ} \mathrm{C}$. This lectin assay of rice (Oryza sativa L.) was miniaturized as only a limited seed sample of each accession was available, and a large number of samples (i.e., 217) had to be analyzed. Thus, 96-welled microplate was used for HA. The ratio of seed flour $(\mathrm{g})$ to protein extraction buffer $(\mathrm{mL})$ was kept the same as used by Bhagyawant et al. [33]. However, this ratio may vary in different studies of plant lectins [2,23].

The U-bottomed microplate was used for HA and the results were recorded through visual observation. In U-shaped wells of microplate strong positive samples appeared as a completely spread lattice while the partially agglutinated showed a diffused button 
and sharp button reflected negative agglutination results. This interpretation may vary from lab to lab or according to the type of microplate (i.e., U-bottomed or V-bottomed) or simple glass slide used [32]. Visual reading of the plate also depends on the concentration of erythrocytes used. Usually, granular appearance of the button and resistance to flow was considered positive.

There is a difference between the extent of HA of different blood types with rice lectins, viz. blood of human (B+) and two rabbits (local and Californian breed) and chicken broiler as observed in the study. Californian breed rabbits' 5\% red cells agglutinated with rice lectins more strongly than the red cells of the local strain and had higher titer (Figure 1a-g. Heard (1955) identified the same results with different rabbit blood groups [38]. Levine and Landsteiner [36] and Kellner and Hedal [37] encountered the same variation in the agglutinability of rabbit RBCs. The 5\% red cells of Californian bred rabbit agglutinated with rice lectins more strongly than the red cells of the local strain, and to a higher titer. Human blood group $\mathrm{B}+(3 \%)$ and $1 \%$ rabbit RBCs did not give precise agglutination results, while 5\% broiler chicken RBCs and 3\% local rabbit RBCs showed clear and satisfactory results (Figure 2). The titer values and specific activities observed for rice kernel lectins may increase with trypsinized rabbit RBCs. However, we have not used trypsin-treated blood for HA [2,16].

The values observed by Peumans et al. 1998 for untreated and trypsin-treated rabbit red blood cells $(0.3$ and $0.6 \mu \mathrm{g} / \mathrm{mL}$, respectively) indicate that the treatment has little effect on HA. Trypsin-treated human erythrocytes agglutinated only at higher concentrations of Calsepa $(5 \mu \mathrm{g} / \mathrm{mL})$, whereas no clear agglutination was observed with untreated human red blood cells [2]. Hirano et al. [16] and Zhang et al. [20] used 1\% trypsinized rabbit RBCs to detect lectins in rice extracts, while Bhagyawant et al. [33] used 3\% trypsin treated rabbit erythrocytes for the detection of legume lectins and Gulzar et al. [32] used 2\% human RBCs for various plants.

Hemagglutination inhibition assay (HAI) was carried for carbohydrate specificity of rice lectins using D-glucose. No apparent inhibition was noticed in the HAI. Therefore, our samples did not show specificity for glucose. Most of the stress-related lectins found in rice are mannose-specific, although glucose specific lectins have also been found in rice [17-24].

According to the analysis of Zhang et al., [20] mannose-binding rice lectins (MRL) have a specific role in plant defense, as they appear exclusively as a response to salt stress. This may also suggest the role of protein-carbohydrate interaction in plant defense against stress. In the same year 2000, Hirano and his coworkers discovered jacalin-related MRL as a mixture of iso-lectins related to salt inducible 'SALT' gene product with constitutive expression as lectin activity was detected in all parts of the plant at all the stages of growth. Furthermore, they argue that some unintentional stress factors during growth, such as water stress, may have induced the jacalin-related MBL expression in rice [16,20].

In short, lectins are a complex group of proteins with structural diversity and an affinity for several carbohydrates; they are involved in a global response, and respond to biotic and abiotic stresses.

\section{Conclusions}

A selected range of indigenous (192) and few exotic (25) rice accessions were investigated for lectin concentrations in this study. They exhibited high HA, reflecting a high lectin concentration in the seeds of wild rice. The findings suggest inclusion of the species in plant breeding programs for lectin alleviation in the cultivated varieties. HA variation for investigated lectins can be utilized for mapping lectin encoding genes governing biotic and abiotic stress resistance in rice as lectins are present in every part of the non-stressed rice plant. Thus, lectins as part of the seed storage proteins can be used as a passive-defense mechanism which might reflect their inherent resistance to biotic and abiotic stresses. Further experiments are needed in this connection to validate the present results in present and other cultivars of rice. 
Author Contributions: H.G., M.A.N., A.J. and F.A.K. performed the experiments. S.N. and M.Z. edited the paper initial and revised version. M.Z. and F.A.K. conceived the idea and supervise the process. D.N., R.U., E.A.A. and H.H. did literature survey and are resource persons. All authors have read and agreed to the published version of the manuscript.

Funding: Researchers Supporting Project Number RSP/2021/45, King Saud University Riyadh, Saudi Arabia.

Data Availability Statement: All related data are within the manuscript.

Acknowledgments: Authors are thankful to Researchers Supporting Project Number RSP/2021/45, King Saud University Riyadh, Saudi Arabia.

Conflicts of Interest: The authors declare no conflict of interest.

\section{References}

1. Peumans, W.J.; van Damme, E.J.M. Plant Lectins: Versatile Proteins with Important Perspectives in Biotechnology. Biotechnol. Genet. Eng. Rev. 1998, 15, 199-228. [CrossRef]

2. Sharon, N.; Lis, H. Lectins as cell recognition molecules. Science 1989, 246, 227-234. [CrossRef]

3. Zhang, N.; Ping, Q.; Huang, G.; Xu, W.; Cheng, Y.; Han, X. Lectin-modified solid lipid nanoparticles as carriers for oral administration of insulin. Int. J. Pharm. 2006, 327, 153-159. [CrossRef] [PubMed]

4. Dan, X.; Liu, W.; Ng, T.B. Development and Applications of Lectins as Biological Tools in Biomedical Research. Med. Res. Rev. 2016, 36, 221-247. [CrossRef] [PubMed]

5. Yau, T.; Dan, X.; Ng, C.C.W.; Ng, T.B. Lectins with Potential for Anti-Cancer Therapy. Molecules 2015, 20, 3791-3810. [CrossRef]

6. Fu, L.-L.; Zhou, C.-C.; Yao, S.; Yu, J.-Y.; Liu, B.; Bao, J.-K. Plant lectins: Targeting programmed cell death pathways as antitumor agents. Int. J. Biochem. Cell Biol. 2011, 43, 1442-1449. [CrossRef] [PubMed]

7. Liu, B.; Bian, H.-J.; Bao, J.-K. Plant lectins: Potential antineoplastic drugs from bench to clinic. Cancer Lett. 2010, 287, 1-12. [CrossRef]

8. Peumans, W.J.; Cammue, B.P.A. Gramineae Lectins: A Special Class of Plant Lectins. In Proceedings of the IUB Symposium No. 144, The Seventh International Lectin Meeting, Bruxelles, Belgium, 18-23 August 1985; pp. 31-38. [CrossRef]

9. Zhang, J.; Shi, J.; Ilic, S.; Xue, S.J.; Kakuda, Y. Biological Properties and Characterization of Lectin from Red Kidney Bean (Phaseolus Vulgaris). Food Rev. Int. 2008, 25, 12-27. [CrossRef]

10. Gautam, A.K.; Shrivastava, N.; Sharma, B.; Bhagyawant, S.S. Current Scenario of Legume Lectins and Their Practical Applications. J. Crop. Sci. Biotechnol. 2018, 21, 217-227. [CrossRef]

11. Gulzar, H.; Pervez, S.; Jan, A.; Nawaz, M.A. Phylogenetics of rice (Oryza sativa L.) genotypes from Pakistan based on diver-sity of biochemical markers. Biosci. Res. 2021, 18, 1681-1693. [CrossRef]

12. Souza, M.A.; Carvalho, F.C.; Ruas, L.; Ricci-Azevedo, R.; Roque-Barreira, M.C. The immunomodulatory effect of plant lectins: A review with emphasis on ArtinM properties. Glycoconj. J. 2013, 30, 641-657. [CrossRef]

13. Chrispeels, M.J.; Raikhel, N.V. Lectins, lectin genes, and their role in plant defense. Plant Cell 1991, 3, 1-9. [CrossRef]

14. Powell, K.; Gatehouse, A.; Hilder, V.A.; Gatehouse, J. Antimetabolic effects of plant lectins and plant and fungal enzymes on the nymphal stages of two important rice pests, Nilaparvata lugens and Nephotettix cinciteps. Entomol. Exp. Appl. 1993, 66, 119-126. [CrossRef]

15. Passricha, N.; Saifi, S.K.; Kharb, P.; Tuteja, N. Rice lectin receptor-like kinase provides salinity tolerance by ion homeostasis. Biotechnol. Bioeng. 2020, 117, 498-510. [CrossRef] [PubMed]

16. Hirano, K.; Teraoka, T.; Yamanaka, H.; Harashima, A.; Kunisaki, A.; Takahashi, H.; Hosokawa, D. Novel mannose-binding rice lectin composed of some isolectins and its relation to a stress-inducible salT gene. Plant Cell Physiol. 2000, 41, 258-267. [CrossRef] [PubMed]

17. Reddy, I.N.B.L.; Kim, B.-K.; Yoon, I.-S.; Kim, K.-H.; Kwon, T.-R. Salt Tolerance in Rice: Focus on Mechanisms and Approaches. Rice Sci. 2017, 24, 123-144. [CrossRef]

18. Claes, B.; DeKeyser, R.; Villarroel, R.; Bulcke, M.V.D.; Bauw, G.; Van Montagu, M.; Caplan, A. Characterization of a rice gene showing organ-specific expression in response to salt stress and drought. Plant Cell 1990, 2, 19-27. [CrossRef]

19. Garcia, A.B.; Engler, J.A.; Claes, B.; Villarroel, R.; van Montagu, M.V.; Gerats, T.; Caplan, A. The expression of the salt-responsive gene sal T from rice is regulated by hormonal and developmental cues. Planta 1998, 207, 172-180. [CrossRef] [PubMed]

20. Peumans, W.J.; Barre, A.; Astoul, C.H.; Rovira, P.; Proost, P.; Truffa-Bachi, P.; Jalali, A.A.H.; van Damme, E.; Zhang, W. Isolation and characterization of a jacalin-related mannose-binding lectin from salt-stressed rice (Oryza sativa L.) plants. Planta 2000, 210, 970-978. [CrossRef] [PubMed]

21. Branco, A.T.; Bernabé, R.B.; Ferreira, B.D.S.; de Oliveira, M.V.V.; Garcia, A.B.; Filho, G.A.D.S. Expression and purification of the recombinant SALT lectin from rice (Oryza sativa L.). Protein Expr. Purif. 2004, 33, 34-38. [CrossRef]

22. Raikhel, N.V.; Lerner, D.R. Expression and regulation of lectin genes in cereals and rice. Dev. Genet. 1991, 12, 255-260. [CrossRef]

23. Jiang, S.-Y.; Ma, Z.; Ramachandran, S. Evolutionary history and stress regulation of the lectin superfamily in higher plants. BMC Evol. Biol. 2010, 10, 1-24. [CrossRef] [PubMed] 
24. Bellande, K.; Bono, J.-J.; Savelli, B.; Jamet, E.; Canut, H. Plant Lectins and Lectin Receptor-Like Kinases: How Do They Sense the Outside? Int. J. Mol. Sci. 2017, 18, 1164. [CrossRef]

25. Munday, J.; Chua, N.-H. Abscisic acid and water stress induce the expression of a novel rice gene. EMBO J. 1988, 7, 2279-2286. [CrossRef]

26. Fadzilla, N.A.M.; Finch, R.P.; Burdon, R.H. Salinity, oxidative stress and antioxidant responses in shoot cultures of rice. J. Exp. Bot. 1997, 48, 325-331. [CrossRef]

27. Hirabayashi, J.; Arai, R. Lectin engineering: The possible and the actual. Interface Focus 2019, 9, 20180068. [CrossRef]

28. Gupta, A.; Gupta, S.; Chaudhary, V.K. Recombinant fusion proteins for haemagglutination-based rapid detection of antibodies to HIV in whole blood. J. Immunol. Methods 2001, 256, 121-140. [CrossRef]

29. Aubert, D.; Foudrinier, F.; Kaltenbach, M.L.; Guyot-Walser, D.; Marx-Chemla, C.; Geers, R.; Lepan, H.; Pinon, J.M. Automated reading and processing of quantitative $\operatorname{IgG}, \operatorname{IgM}, \operatorname{IgA}$, and IgE isotypic agglutination results in microplates Development and application in parasitology-mycology. J. Immunol. Methods 1995, 186, 323-328. [CrossRef]

30. Lorbach, J.N.; Wang, L.; Nolting, J.M.; Benjamin, M.G.; Killian, M.L.; Zhang, Y.; Bowman, A.S. Porcine Hemagglutinating Encephalomyelitis Virus and Respiratory Disease in Exhibition Swine, Michigan, USA, 2015. Emerg. Infect. Dis. 2017, 23, 1168-1171. [CrossRef]

31. Wood, J.M.; Major, D.; Heath, A.; Newman, R.W.; Höschler, K.; Stephenson, I.; Clark, T.; Katz, J.M.; Zambon, M.C. Reproducibility of serology assays for pandemic influenza H1N1: Collaborative study to evaluate a candidate WHO International Standard. Vaccine 2012, 30, 210-217. [CrossRef]

32. Gulzar, H.; Gul, J.; Hassan, G. Protein profiles of phytoagglutinins from indigenous species of Euphorbiaceae, Leguminosae and Moraceae from Pakistan. Pak. J. Bot. 2015, 47, 119-126.

33. Bhagyawant, S.S.; Gautam, A.; Chaturvedi, S.K.; Shrivastava, N. Hemagglutinating activity of Chickpea extracts for lectin. Int. J. Pharm. Phytopharm. Res. 2017, 5, 15-21.

34. Bing, D.H.; Weyand, J.G.M.; Stavitsky, A.B. Hemagglutination with Aldehyde-Fixed Erythrocytes for Assay of Antigens and Antibodies. Exp. Biol. Med. 1967, 124, 1166-1170. [CrossRef]

35. Heard, D.H. Factors influencing the agglutinability of red cells. Variation of the red cells of the rabbit in susceptibility to ag-glutination by homologous iso-antisera. Epidemiol. Infect. 1955, 53, 408-419. [CrossRef]

36. Levine, P.; Landsteiner, K. On immune isoagglutinins in rabbits. J. Immunol. 1929, 17, 559-564.

37. Kellner, A.; Hedal, E.F. Experimental Erythroblastosis Fetalis in Rabbits. J. Exp. Med. 1953, 97, 33-49. [CrossRef] [PubMed]

38. Nakata, H.; Lin, C.Y.; Abolhassani, M.; Ogawa, T.; Tateno, H.; Hirabayashi, J.; Muramoto, K. Isolation of Rice Bran Lectins and Characterization of Their Unique Behavior in Caco-2 Cells: Characterization of a pair of allelic blood group fac-tors and their specific immune isoantibodies. Int. J. Mol. Sci. 2017, 18, 1052. [CrossRef] [PubMed]

39. Wang, H.; $\mathrm{Ng}, \mathrm{T} . ; \mathrm{Liu}, \mathrm{Q} . \mathrm{B}$. Isolation of a new heterodimeric lectin with mitogenic activity from fruiting bodies of the mushroom Agrocybe cylindracea. Life Sci. 2002, 70, 877-885. [CrossRef]

40. Bradford, M.M. A rapid and sensitive method for the quantitation of microgram quantities of protein utilizing the principle of protein-dye binding. Anal. Biochem. 1976, 72, 248-254. [CrossRef]

41. Sun, J.-P.; Hou, C.-Y.; Feng, J.; Wang, X. Determination of the protein content in rice by the digital chromatic method. J. Food Qual. 2008, 31, 250-263. [CrossRef]

42. Adenike, K.; Eretan, O.B. Purification and partial characterization of a lectin from the fresh leaves of Kalanchoe crenata (Andr.) Haw. J. Biochem. Mol. Biol. 2004, 37, 229-233. [CrossRef] [PubMed] 